\title{
PSYCHE
}

Vol. 63

March, 1956

No. 1

\section{AUSTRALIAN CARABID BEETLES III. NOTES ON THE AGONINI ${ }^{1}$}

\author{
By P. J. Darlington, JR. \\ Museum of Comparative Zoology, Cambridge, Mass.
}

One of the interesting things in the geography of carabid beetles is that certain dominant groups of them have complementary distributions. For example, among small, ground-living but non-fossorial Carabidae, the great genus Tachys is dominant in the tropics but diminishes northward and southward; and it is largely replaced in the north-temperate zone and to some extent in some southtemperate areas by another great, related genus, Bembidion, which is very poorly represented in the tropics ( $c f$. Darlington, Coleopterists' Bulletin Vol. 7, No. 2, 1953, pp. 12-16).

Two other tribes of larger Carabidae which have somewhat complementary distributions are the Pterostichini and Agonini. These tribes are only partly and very complexly complementary. Both are in fact cosmopolitan, but unevenly so. In some places, they occur in nearly equal numbers; in other places, Pterostichini are overwhelmingly dominant; and in others, Agonini are so.

These tribes tend to be complementary within the Australian region. In Australia itself and Tasmania Pterostichini are dominant, with more than 350 known species against only about 20 species of Agonini in the same area. But in New Guinea Agonini are dominant, with 107 known full species and 14 additional geographical subspecies

\footnotetext{
${ }^{1}$ Published with a grant from the Museum of Comparative Zoology at Harvard College.
} 
(Darlington, Bull. Mus. Comp. Zool. Vol. 107, No. 3, 1952, pp. 89-252, pls.) against only about 20-odd species of Pterostichini (in material assembled for study but not yet formally studied).

One reason for the number of Agonini in New Guinea is that species of this tribe have multiplied on the mountains there, in forest at middle and high altitudes. Some of them occur even in the high grasslands above the forest line, at 11,000 feet or higher, where the climate is colder than it is in much of Australia. In Australia, however, Pterostichini, not Agonini, have multiplied on the mountains. Why this should be so is not immediately apparent. The Australian mountains are lower, but this does not account for the difference. On the Atherton Tableland and elsewhere in tropical Queensland in northeastern Australia, at altitudes of 2,000 or 3,000 feet, are big tracts of full-scale rainforest (called "scrub" in Australia) entirely comparable to the rainforests of New Guinea and containing some of the same species of trees. This kind of forest in New Guinea is inhabited by many Agonini and few Pterostichini; but in Australia, by few Agonini and many Pterostichini, most of the latter belonging to Australian genera which do not reach New Guinea at all. I have collected extensively in both the Australian and New Guinean rainforests, and I can testify from my own experience that the pterostichine-agonine faunas of the two places are unexpectedly and profoundly differont - in spite of the fact that they share some identical species!

This difference can hardly be accounted for in simple ecological terms but is probably due to a complex combination of ecological, historical, and geographical factors. Over the world as a whole, there is a tendency for Agonini to be better represented in the tropics; Pterostichini, in the temperate zones; although this zonal complementarity is not strongly defined. Also it is probable that the Agonini are more recent in origin than the Pterostichini and that they have dispersed more recently, although the dispersal of each group has been very complex, and although even the Agonini dispersed long enough ago to have reached all 
parts of the world and to have differentiated to some extent in different regions. I base this guess, of the more recent rise and dispersal of Agonini, chiefly on the lesser diversity of this tribe as compared with the Pterostichini. If all this is correct, it may be guessed that Pterostichini are dominant in Australia partly because Australia is more temperate than tropical in climate, and partly because the Pterostichini reached Australia before Agonini did; and it may be guessed that Agonini are dominant in New Guinea partly because the climate there is fully tropical, and partly because the carabid fauna of New Guinea is more recent in its origins than that of Australia. Add to this that the mountain carabid faunas of Australia and New Guinea have been derived independently, each from the lowland fauna adjacent to it, and not by dispersal along a connecting mountain chain, and we have an adequate and probably correct explanation of the unexpected difference in composition of the carabid faunas in the mountain rainforests of Australia and New Guinea.

Whether or not this explanation is correct, the situation among Carabidae suggests that, although Australia and New Guinea were connected by land at times in the Pleistocene (perhaps as recently as ten thousand years ago) and although some species crossed the connection, rainforest and mountain habitats were not fully continuous and whole faunas were not exchanged.

Sloane (Proc. Linn. Soc. N. S. W., Vol. 35, 1910, pp. 453-458) revised the Australian Agonini ("Sphodrini") known to him, recognizing 4 genera and 10 species not including Homothes, which he transferred to this tribe ("Anchomenini") in 1920 (Proc. Linn. Soc. N. S. W., Vol. 45 , p. 164). However, some of his generic assignments, although correct according to the usage of his time, are now known to be wrong and misleading. I therefore offer the following new key to the Australian genera of Agonini (Sphodrini, Anchomenini). This key is still preliminary in some ways, but it puts the Australian forms in line with the New Guinean ones and disposes of the most misleading assignments.

The following key applies only to Australian species of 
the genera in question. In the case of genera represented in Australia by single species, the species are characterized and named in the key. A comparable key to New Guinean Agonini is given in my paper cited above, pages 114-116.

Preliminary key to Australian genera of Agonini

1. Tarsi sparsely pubescent above; tarsal claws serrate on inner edge in basal half; (relatively large, c. 13-15 mm., dull black; introduced) .... Laemostenus complanatus Dej.

- Tarsi not pubescent above; claws not serrate .... 2

2. Tarsal claws each with an acute tooth on inner edge at base; (winged, brown, rather slender, prothorax suboval) ..........Dicranoncus queenslandicus (Sl.)

- Tarsal claws not toothed ................ 3

3. Wings full and all normal setae of head and pronotum present ........................ 4

- Wings vestigial and/or one or more pairs of supraocular or lateral prothoracic setae absent ....... 7

4. Sole of hind tarsus with a single, regular row of bristles on each side, with middle of sole bare; (slightly aeneous, Agonum-like) ...... Lorostemma cooki (Sl.)

- Bristles of hind-tarsal sole not as above ....... 5

5. Brown, bronzed, or black; last hind-tarsal segment without accessory setae at sides below; elytra (in Australian species) not spined ......... Notagonum

- Purple (or blue), at least on elytra . . . . . . . . 6

6. Last hind-tarsal segment with accessory setae; elytra not spined; (prothorax narrow; elytra wide, purple)

Colpodes porphyriacus (Sl.)

- Last hind-tarsal segment without accessory setae; elytra spined at apex about opposite second intervals; (prothorax rather wide; color purple or bluish-purple)

Violagonum (n. gen.) violaceum (Chd.)

7. Wings full; humeri normal; (depressed; dull brown or black, often margined or finely speckled with pale)

Homothes

- Wings vestigial; humeri dentate; (convex; shining black) ...... Odontagonum (n. gen.) nigrum n. sp. 


\section{List of genera}

Laemostenus (or Laemosthenes) is a Palearctic genus. L. complanatus Dej. is native to the sub-desert regions of North Africa. It has been introduced around the Mediterranean, on several Atlantic islands, in western North America, southern South America, and parts of Australia and Tasmania, etc.

Dicranoncus is a mainly Oriental genus. D. queenslandicus (Sl.) extends from India and the Philippines to North Queensland. In the Philippines (on Luzon) I found it living in clumps of tall grass in open country.

Lorostemma is an Oriental-Australian genus. L. cooki (Sl.) occurs from North Queensland south at least to Brisbane, where I took a series in flood debris in Oct.Nov., 1943. It resembles $L$. informalis Darl. of New Guinea, but has a smaller prothorax with narrower margins. I have not made a more detailed comparison.

Notagonum is a genus of convenience, proposed for a number of relatively unspecialized New Guinean species which resemble the northern Agonum but do not really belong to it. I tentatively assign to Notagonum about 8 Australian species. Most of them have heretofore been listed as Agonum, Platynus, Anchomenus, or Europhilus, but these genera are all primarily northern and do not occur in the Australian Region. I shall not discuss these species in detail, except (below) to record one of them from Australia for the first time and to describe another as new.

Colpodes, as used here, is another genus of convenience not sharply separable from Notagonum, but containing usually more specialized, larger, often more brightly colored, often arboreal rather than terrestrial species. The only Australian species here assigned to Colpodes is porphyriacus (Sl.), which is known to me only by description. Of two other "Colpodes" listed by Sloane (1910), one (lafertei Mont.) is here tentatively assigned to Notagonum, and the other (violaceus Chd.) is placed in a new genus (below). 
Violagonum is a new, monotypic genus proposed for Colpodes violaceus Chd. of New Guinea etc. and North Queensland.

Homothes is a primarily Australian genus, with half a dozen or more species in Australia and Tasmania. The genus is now known to have an endemic species also in Java and Luzon (Louwerens, in Treubia, Vol. 21, 1952, pp. 215-217).

[Aeolodermus emarginatus (Chd.), related to Homothes and described as from Victoria, is probably not Australian. It occurs from the Malay Peninsula to Celebes and the Philippines.]

Odontagonum is a new, monotypic genus based on a new species from North Queensland.

This list of genera shows that the native Agonini of Australia, heretofore thought to include geographically isolated representatives of several north-temperate genera, actually consist of the following:

Two chiefly Oriental genera which extend to northeastern Australia: Dicranoncus is represented in Australia by a widely distributed Indo-Australian species; Lorostemma, by a slightly defined endemic species.

One mainly New Guinean genus and species, Violagonum violaceum, which extends to North Queensland without differentiation.

Two tentative genera of convenience, Notagonum and Colpodes, with about 9 , mostly relatively unspecialized Australian species. One of these species, Notagonum dentellum, is mainly New Guinean; 1, Notagonum lafertei, shared with New Caledonia; and 1, Notagonum submetallicum, shared with New Zealand.

One genus, Homothes, which is chiefly Australian but represented in Java etc. by an endemic species.

And one probably autochthonous (but not necessarily very old), flightless genus and species, Odontagonum nigrum, confined to North Queensland.

The general nature of this fauna is consistent with the Agonini being relatively recent in Australia, and having accumulated there by successive arrivals from (or exchanges with) the Orient and New Guinea. 
New records and descriptions

Notagonum dentellum Darl.

Darlington 1952, Bull. Mus. Comp. Zool. Vol. 107, 147.

This species, which is widely distributed in New Guinea, occurs also in North Queensland. I took two specimens of it at Millaa Millaa, on the Atherton Tableland, in April, 1932.

\section{Notagonum nigrellum n. sp.}

With characters of genus as defined in my paper on New Guinean Agonini, pages 127-129. Form of rather slender Agonum; black, appendages dark, margins of prothorax and elytra not pale; upper surface moderately shining, not iridescent, not punctate; microsculpture isodiametric on head, slightly transverse on pronotum and elytra. Head .77 and .77 (in $\hat{\alpha} \circ$ measured) width prothorax; eyes large, moderately prominent; posterior supraocular setae about between posterior edges of eyes. Prothorax: width/length 1.29 and 1.29 (in of of measured); base/apex 1.32 and 1.25; sides rather broadly arcuate, sometimes subangulate at anterior marginal setae, converging and nearly straight or slightly sinuate before posterior angles; latter obtuse, usually slightly blunted; lateral margins rather narrow; basal foveae rather shallow, not or vaguely punctuate; anterior marginal line entire or nearly so, posterior one vague at middle. Elytra moderately wide; humeri rounded, sides behind humeri nearly straight and slightly diverging, then increasingly arcuate to moderate subapical sinuations; apices rounded or slightly denticulate (variable) at sutural angles; striae well impressed, not or faintly punctulate; intervals moderately convex, outer ones not much modified toward apex, 3rd with 3 normally placed punctures. Lower surface virtually impunctate; abdomen not pubescent. Fourth hindtarsal segment rather deeply emarginate but not strongly lobed. Length, about 8-9; width, 2.9-3.4 mm.

Holotype of (M. C. Z. Type No. 29,461) and 22 paratypes all from Mt. Kosciusco, 5,000-7,000 ft. altitude, Dec. 1931, taken by myself probably (if my memory is correct) beside brooks. 
This new species is probably related to Notagonum ("Anchomenus") marginellus (Er.), but differs from it and from other related species in being entirely black and in having narrower prothoracic margins.

Violagonum n. gen.

Broad Agonum-like in form; color (in single known species) purple or purplish-blue. Head rather short (not elongate as in Colpodes) ; mentum toothed; mouth parts and antennae normal; both pairs supraocular setae present. Prothorax rather wide, with usual 2 pairs lateral pronotal setae. Elytra each with a spine at apex about opposite 2nd interval; striae normal; intervals normal except 9th narrowed apically (above subapical sinuations) ; 3rd normally 3-punctate. Inner wings full. Legs and tarsi normally agonine; tibiae not sulcate on outer edges; hind tarsi sulcate on each side above, with setae not forming single regular rows on each side below; 4th hind-tarsal segment lobed, outer lobe much longer than inner; 5th hind-tarsal segment without obvious accessory setae; claws simple. External sexual characters normal for tribe. Genotype: Colpodes violaceus Chd.

Although the species for which this new genus is proposed was, as a matter of convenience, left in Colpodes in my paper on New Guinean Agonini, it is not a true Colpodes. The short head particularly distinguishes it. The position of the elytral spines distinguishes it from the few species of Notagonum that have spines: in Notagonum, the spines (when present) are about opposite the ends of the 3rd elytral intervals. The lobes of the 4th hind-tarsal segment are longer than in most Notagonum. And the general form and color of Violagonum are distinctive, though not themselves of generic value.

Odontagonum $n$. gen.

Genus proposed for one medium-sized, flightless, convex Agonum-like species with two characters which, so far as I know, are unique among Agonini: antennae pubescent from the middle of the 3rd (not 4th) segments, and humeri toothed. Since the genus is based on one species, other generic and specific characters are all combined in 
the following specific description. Genotype: Odontagonum nigrum n. sp., below.

Odontagonum nigrum n. sp.

Form of a broad, very convex Agonum; black, moderately shining, not iridescent, legs brownish black, antennae and mouth parts brown; upper surface impunctate except for fixed setigerous punctures; microsculpture light but normal, approximately isodiametric on head, transverse on pronotum, more transverse and oblique on elytral disk. Head rather elongate, only .57 and .59 width prothorax (in $\hat{\alpha}+\frac{q}{\text { measured) }}$; eyes much less prominent than in typical Agonum but not much reduced otherwise; genae rather short, oblique, slightly arcuate; anterior supraocular setae absent, posterior ones present, about between posterior edges of eyes; antennae rather short (in tribe), normal except pubescent from middle of 3rd (not 4th) segments; mandibles, maxillae, and maxillary palpi all longer and more slender than usual in tribe; labial palpi shorter and stouter; mentum with triangular tooth; neck constriction weak; frontal sulci rather deep, linear, curved; clypeal suture distinct. Prothorax rather large, more narrowed in front than behind; width/length 1.18 and 1.11 (in of o measured); base/apex $1.3+$; sides arcuate (not strongly) for most of length, less so or straight toward base; basal angles rather narrowly rounded; anterior angles slightly produced, rather narrowly rounded; lateral margins wide posteriorly, narrowed anteriorly, rather strongly reflexed, each with seta about $1 / 3$ from apex but none at base; disk convex; basal foveae moderate, not sharply defined, not punctate; middle line well impressed from extreme base nearly to apex; transverse impressions less defined; base not or vaguely margined; apical marginal line distinct at sides, vague at middle. Elytra 1.32 and 1.31 width prothorax (in $\hat{\alpha}$ o measured), convex; basal margin strong and entire; humeri dentate; sides arcuate (only slightly so at middle), with moderate subapical sinuations; apices bluntly subacute but not produced; lateral margins rather wide, forming slightly convex 10th intervals; sutural striae absent; other striae entire, deep, impunctate; intervals 
convex, 7 th subcostate in about anterior $1 / 2$ of length, outer ones not much modified toward apex, 3rd with 1 setigerous puncture, near middle of length. Inner wings evidently vestigial; metepisterna scarcely longer than wide. Lower surface impunctate; abdomen not pubescent. Tibiae not sulcate on outer edges; hind tarsi slender, not distinctly grooved above; 4th hind-tarsal segment simply emarginate; 5th segment with 2 or 3 accessory setae each side below. External sexual characters normal; $\hat{o}$ front tarsi more widely dilated than usual in tribe. Length about 11.0-11.5; width about 4.0-4.3 $\mathrm{mm}$.

Holotype (M. C. Z. Type No. 29,462) ô from Millaa Millaa, Atherton Tableland, North Queensland, 2,500 ft. altitude. Two ( 0 o ) paratypes from Lake Barrine, Atherton Tableland, 2,300 ft. All specimens taken by myself in "scrub" (rainforest), in April, 1932. 

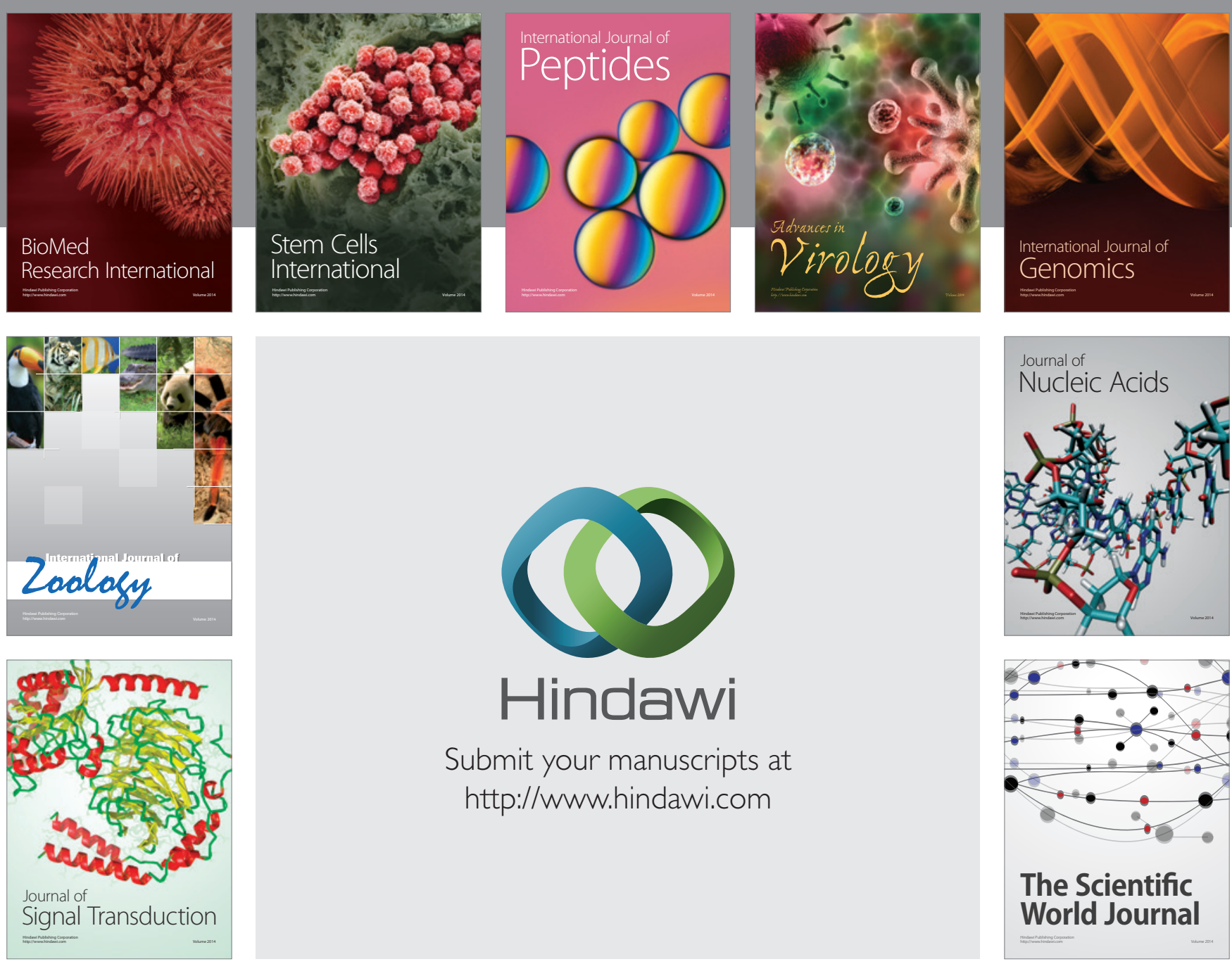

Submit your manuscripts at

http://www.hindawi.com
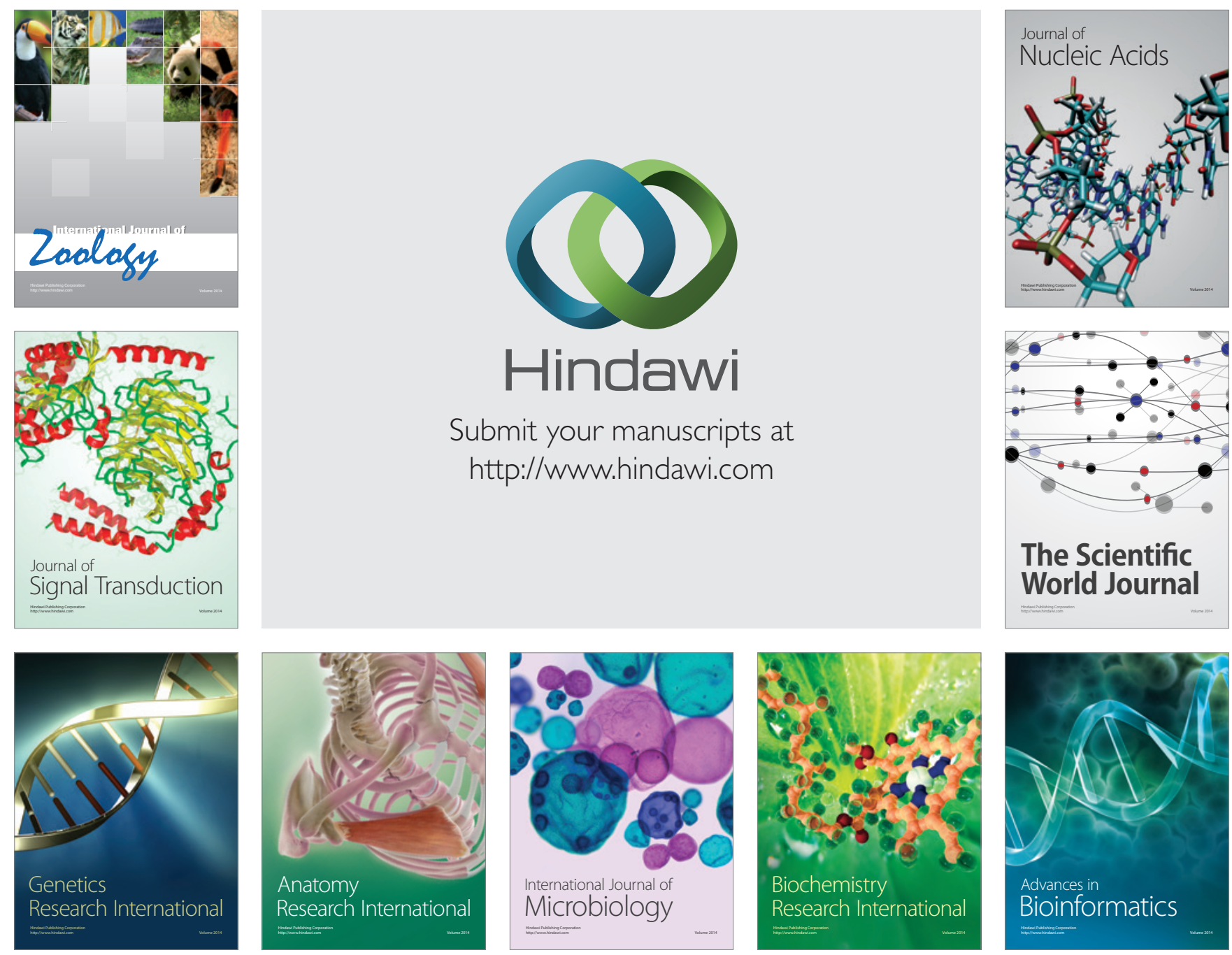

The Scientific World Journal
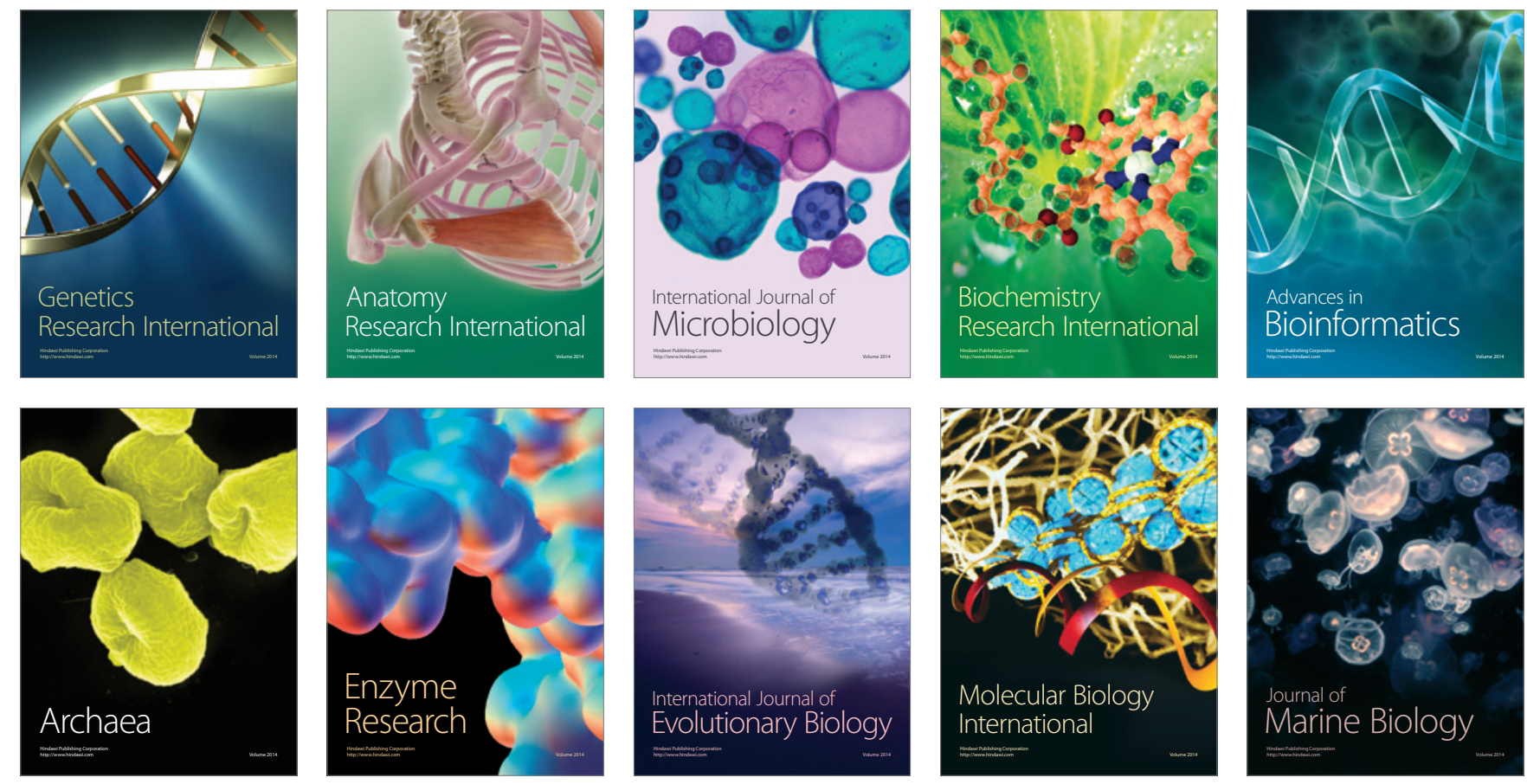